\title{
CONSIDERAÇÕES SOBRE O DIREITO AO ESQUECIMENTO NO BRASIL E NA
} UNIÃO EUROPEIA

\author{
Sâmia Souza Carvalho* \\ Taysa Pacca Ferraz de Camargo ${ }^{* *}$ \\ Caio Pacca Ferraz de Camargo ${ }^{* * *}$
}

\section{Resumo}

O presente estudo tem por objetivo geral esclarecer que existe diferença no conceito de direito ao esquecimento no Brasil em relação à União Europeia. Tenciona-se, especificamente, apresentar que existem formas variadas de se entender o conceito em comento. O presente artigo se desenvolverá com pesquisa bibliográfica construída por meio de doutrina nacional e internacional, além de jurisprudência brasileira e europeia e o método utilizado será o dedutivo. Ao final, conclui-se pela multiplicidade de contextos aos quais o instituto se aplica. Em suma, os conceitos brasileiros e europeus não são sinônimos e, portanto, têm tutelado direitos distintos.

Palavras-chave: Direito ao esquecimento; Desindexação; Direito fundamental; Sociedade informacional; União Europeia.

\section{CONSIDERATIONS ON THE RIGHT TO BE FORGOTTEN IN BRAZIL AND IN THE EUROPEAN UNION}

\begin{abstract}
The present study aims to endure that there is a difference on the concept of right to be forgotten in Brazil in relation to the European Union. It is intended, specifically,to present that there are varied ways of understanding this concept in commentary. . This paper will be developed with bibliographic research built by national and international doctrine, besides, brazilian jurisprudence and european also the method used will be deductive. At the end, it is concluded by the multiplicity of contexts to which the institute applies. In short, brazilian and european concepts are not synonymous and therefore has tutelated diverse rights.
\end{abstract}

Keywords: Right to be forgotten; Delisting; Fundamental right; Information society; European Union.

\footnotetext{
${ }^{*}$ Mestranda em Direito.

** Mestranda em Direito. Especialista em Direito Civil e Direito Notarial e Registral Imobiliário. Bacharel em Direito. Conciliadora Judicial do TJSP. Lattes: http://lattes.cnpq.br/7228338839777576.

*** Mestre em Direito. Mestrando em Direito da Sociedade da Informação. Especialista em Direito Civil e Notarial e Registral. Bacharel em Direito e Relações Internacionais. Registrador Civil e Notário/SP. Lattes: http://lattes.cnpq.br/7228338839777576.
} 


\section{INTRODUÇÃO}

No presente artigo, parte-se da ideia de que o instituto do direito ao esquecimento tomou novos contornos com a sociedade da informação, de modo que, memória digital e analógica são distintas e merecem, portanto, tutelas diversas. Nessa esfera, com a profusão das informações compartilhadas via web e, sobretudo, pelo julgamento do caso Costeja na União Europeia, em 2014, o termo em questão tem sido delineado para além da esfera penal. No Brasil, o Supremo Tribunal Federal (STF) já havia reconhecido a repercussão geral $n^{\circ} 786$ a respeito do tema e, em fevereiro de 2021, procedeu-se ao julgamento. No entanto, tal decisão não coloca fim à discussão que ora se pretende propor.

Partindo do cenário apresentado, tem-se que o objetivo geral do artigo é esclarecer que existe diferença no conceito de direito ao esquecimento no Brasil em relação à União Europeia. Intenta-se demonstrar que os conceitos brasileiros e europeus não são sinônimos e, portanto, tutelam direitos distintos. Assim, tenciona-se, especificamente, apresentar que existem formas variadas de se entender o conceito de direito ao esquecimento e, por isso, o termo é impreciso e impróprio para certos casos, como, por exemplo, de desindexação.

Deste modo, propõem-se os tópicos: Considerações sobre o direito ao esquecimento no Brasil e na União Europeia; Right to erasure ("right to be forgotten") na União Europeia; Direito ao esquecimento e desindexação no Brasil; Principais diferenças do caso paradigmático da União Europeia e do Brasil e, por fim, as Considerações finais.

O presente artigo se desenvolverá com pesquisa bibliográfica construída por meio de doutrina nacional e internacional, além de jurisprudência brasileira e europeia. Pretende-se, sem prejuízo de outros tribunais, utilizar a jurisprudência do STF e TJUE, dado que os casos paradigmáticos de direito ao esquecimento foram decididos por ambos tribunais cada qual em sua jurisdição. Além disso, será feito uso do regulamento geral europeu, qual seja, General Data Protection Regulation (GDPR). O método utilizado será o dedutivo, partindo-se inicialmente de uma visão geral sobre o assunto para, na sequência, enfrentar a questão central que se coloca: existe, atualmente, distinção no conceito de direito ao esquecimento, derivado dos casos paradigmáticos no Brasil e na União Europeia, e isso pode engendrar incertezas quanto ao que tal instituto é capaz de tutelar?

Além disso, o presente estudo é relevante na medida em que busca aclarar as diferenças entre o caso brasileiro e o europeu. Nesse sentido, também, justifica-se, pois, existe 
uma confusão acerca do conceito em tela o que pode impactar na sua tutela jurídica. A doutrina e a jurisprudência brasileiras não definiram os termos exatos do que seria direito ao esquecimento. Embora, nos últimos anos tenha havido um esforço nesse sentido. A imprecisão na definição do termo e de seu alcance ocasionam certa confusão à primeira vista, o que pode ter ocasionado, recentemente, a incompreensão no que concerne ao não reconhecimento do direito ao esquecimento na esfera cível, pelo STF .

Na Europa, conforme veremos a seguir, o caso emblemático se refere à desindexação de provedor de pesquisa na internet, enquanto, no Brasil, o caso paradigmático é anterior à ebulição da internet e versa sobre direito de imagem e indenização em virtude de utilização não autorizada. Nessa esfera, o uso do termo tem servido a diferentes demandas: desindexação em buscador, legislação de proteção de dados para os controladores que realizam tratamento, apagamento de fatos ilícitos do passado e, por vezes, até do presente, além de solicitações de exclusão de conteúdo em página da web.

No panorama ora apresentado o instituto em tela ainda é capaz de gerar discussões acerca do acesso à informação, da liberdade de expressão, da privacidade, da honra e da memória pública coletiva lançando luz sobre a ponderação de princípios constitucionais. Diante do exposto, a ideia do direito ao esquecimento tem sido utilizada para contextos distintos dificultando sua uniformidade e engendrando confusões conceituais e jurídicas, conforme será visto nos tópicos a seguir.

\section{CONSIDERAÇÕES SOBRE O DIREITO AO ESQUECIMENTO NO BRASIL E NA UNIÃO EUROPEIA}

Inicialmente, faz-se necessário explicitar o contexto em que o tema do direito ao esquecimento surgiu. Os primeiros estudos sobre a questão estão entrelaçados ao direito à privacidade. Nos Estados Unidos, o Tribunal de Apelações da Califórnia, em 1931, manifestou-se acerca da violação da privacidade e pela possibilidade de ser esquecido por um evento passado. Bobadilla considera o caso Melvin v. Reid um dos primeiros a reconhecer jurisprudencialmente o direito em comento. A autora elucida:

Desde la publicación del artículo de Warren y Brandeis, y durante las dos primeras décadas del siglo XX, en Estados Unidos se empezó a forjar una postura favorable hacia la protección de este derecho, que dio paso a que en los años 30 ya se puedan encontrar los primeros casos en los que los ciudadanos no solamente reclaman por su privacidad, sino también por el olvido.Fue precisamente este país uno de los 
primeros en resolver un caso de derecho al olvido anterior a la era digital: el Caso Melvin v. Reid en 193110, en el que la Corte de Apelaciones de California consideró que los hechos habían producido una violación en la privacidad de la señora Darley, y que las personas deben tener derecho a olvidar y a ser perdonadas.Este se convirtió en uno de los casos más emblemáticos en esta materia, ya que se puede considerar que es un reconocimiento jurisprudencial del derecho al olvido, del derecho a tener una segunda oportunidad, donde se pueden olvidar los hechos del pasado cuando ya no tienen relevancia para la conformación de la opinión pública del presente, y guardando el delicado equilibrio que es necesario mantener entre los derechos de la personalidad y el derecho a la información. (BOBADILLA, 2020).

A Alemanha também é considerada precursora no assunto, com o julgamento do caso Lebach, em 1969. Neste caso, o cidadão já havia cumprido sua pena, mas um programa de televisão queria reconstruir a história, contudo, preventivamente, ingressou-se com a ação. Oliveira explica:

O caso retrata o julgamento ocorrido em 1969 na Alemanha a respeito de um cidadão que supostamente esteve envolvido no assassinato de quatro soldados alemães na cidade de Lebach. Tendo esse cidadão já cumprido a sua pena, pouco antes de sua liberação, um programa de televisão decide recontar a história utilizando o nome desse cidadão que já havia cumprido a sua pena. Nesse momento, ajuizada ação com o objetivo de impedir que o referido programa fosse ao ar, uma vez que a lembrança de tais fatos poderia ser interpretada fora de seu contexto atual, bem como teria o potencial de ocasionar danos ao cidadão que já havia cumprido a sua pena. O Tribunal Constitucional Alemão reconheceu nesse caso o direito de o cidadão ser "esquecido" por entender que a reconstituição dos fatos, por meio do programa de televisão, exporia o acusado a danos injustos em virtude do cumprimento da pena que lhe havia sido imposta. (OLIVEIRA, 2020).

Assim, construíram-se a base teórica e os primórdios do direito ao esquecimento. Contudo, a profusão dos dados na era digital deu novas proporções e peculiaridades às ideias de privacidade, acesso à informação e liberdade de expressão, as quais se diferem da era analógica. Assim, em 2012, na União Europeia, a discussão ganhou novos rumos, conforme aponta Pérez:

Los datos que los usuarios suben a Internet dejan de ser privados al momento que
forman parte del ciberespacio, puesto que aunque se utilicen archivos encriptados o
herramientas de seguridad, igualmente dichos mecanismos pueden ser violados no
solo por hackers, tal como ocurrió con la compañía Sony Pictures y el disco de
Madonna a en 2014, sino por cualquier persona un tanto más avezada que el
promedio en materia informática. Pero, además, dichos datos deberían ser
susceptibles de ser borrados de la Web cuando los usuarios lo estimen conveniente,
independientemente de cuál sea la razón. Sin embargo, esto hasta el momento no
ocurre, por lo que en enero de 2012 la Unión Europea propuso el "Derecho de ser
olvidado" (the right to be forgotten. (PÉREZ, 2016).

Nessa seara, conforme veremos no tópico a seguir, em 2014, os mecanismos de buscas na internet reacenderam a pertinência da discussão sobre o assunto. Assim, se 
evidencia que o termo "direito ao esquecimento" não se relaciona somente a casos oriundos da internet. Embora o caso de maior repercussão e que deu os contornos tais quais como se conhece o instituto atualmente tenha sido o caso espanhol de 2014. Rincón elucida que o caso Costeja representa um marco sobre o direito ao esquecimento na internet:

La primera vez que se habló del derecho al olvido fue en la sentencia del Tribunal de
Justicia de la Unión Europea el 13 de mayo de 2014 . En ese momento, el TJUE
resolvió el caso de un ciudadano español en contra de Google por el tratamiento de
sus datos mediante el buscador, de acuerdo con la entonces Directiva $95 / 46$ sobre
protección de datos, que vino a representar el leading case del derecho al olvido en
Internet. Dos años después de esa sentencia, se aprobó el actual Reglamento General
del Parlamento Europeo y del Consejo, del 27 de abril de 2016,2 cuyo artículo 17
contempla el derecho al olvido.La sentencia del Tribunal supranacional planteó
diversas cuestiones en torno a la configuración del derecho al olvido. Una de las
cuestiones que se destacó más allá incluso de los pronunciamientos sobre el
tratamiento de datos o la responsabilidad de los buscadores en Internet es si la
sentencia configuró el derecho al olvido como un derecho fundamental, o bien como
una nueva denominación adoptada de alguna de las facultades existentes del derecho
a la protección de datos personales (véase Arenas 2013, derechos ARCO).
(RINCÒN, 2019).

A partir do caso explicitado acima será vista, no próximo tópico, a configuração do termo na União Europeia. Na sequência, serão verificadas as características do instituto no Brasil, a fim de que, no último tópico seja possível aclarar a distinção entre ambos cumprindo o escopo deste trabalho.

\subsection{RIGHT TO ERASURE ("RIGHT TO BE FORGOTTEN”) NA UNIÃO EUROPEIA}

Os contornos do termo na União Europeia também têm origem jurisprudencial, derivada do caso C-131/12 (Google Spain SL e Google Inc. contra Agencia Española de Protección de Datos (AEPD) e Mario Costeja González). Embora, atualmente, após a entrada em vigor da General Data Protection Regulation (GDPR), em 2018, o instituto também esteja expresso. Portanto, já reconhecido pela legislação europeia, conforme artigo 17 da GDPR Right to erasure ("right to be forgotten") (UNIÂO EUROPEIA, 2018). Rincón aclara o panorama do caso europeu:

En el ámbito europeo, la configuración de los contornos del derecho al olvido recayó en manos del Tribunal de Justicia de la Unión Europea (TJUE), al resolver en 2014 la cuestión prejudicial planteada por la Audiencia Nacional con motivo de un recurso interpuesto por Google contra la Agencia Española de Protección de Datos (AEPD). Paralelamente, la Comisión Europea ha considerado indispensable actualizar el marco jurídico existente para incluir el reconocimiento y alcances del derecho al olvido. Con este fin, en 2012 la Comisión Europea presentó una Propuesta de Reglamento General de Protección de Datos (Reglamento General), 
que fue aprobada en 2016, con su artículo 17 sobre la regulación del derecho al olvido. (RINCÓN, 2019).

Deve-se atentar que o citado artigo 17 da GDPR traz duas nomenclaturas em sua composição. Acerca da dupla nomenclatura Tamó e George apontam “(..) the fact that the right was re-labelled as the right of erasure reflects policy makers ambiguity towards the terminologyused" (TAMÒ; GEORGE, 2014). Na versão em português do site oficial da GDPR a tradução aparece da seguinte forma "Direito ao apagamento dos dados (direito a ser esquecido)" (UNIÃO EUROPEIA, 2018).

Nessa esfera acerca da terminologia elucida Belay que "apesar da sua popularização graças à decisão do caso Google versus Espanha, (...) o termo 'direito ao esquecimento' continua sendo motivo de confusões" (BELAY, 2016). Partindo da ideia de que existe um desajuste em relação ao termo externa-se o conceito apresentado por Alcón:

El derecho al olvido es una "forma poética de referirse principalmente al derecho de
cancelación, y eventualmente también al de oposición, en el marco del derecho
fundamental de la protección de datos" (Simon, 2015, pp. 97-102). Este derecho, en
la práctica, es utilizado por los ciudadanos que observan que las nuevas tecnologías
no les son afines, y descubren que circula, por las redes sociales o por los motores de
búsqueda, información sobre ellos, información perjudicial para sus propios
intereses, y desean hacer desaparecer esos datos, en ocasiones inexactos, en
ocasiones falsos o en ocasiones irrelevantes, todas estas consideraciones siempre
realizadas desde el punto de vista del eventual reclamante. (ALCÓN, 2016)

Tal conceito fora explicitado, apenas, para evidenciar de que trata o instituto, uma vez que a doutrina europeia reconhece a complexidade dessa questão terminológica. Não existe uniformidade em relação ao termo, isto é, não se utiliza apenas o termo "right to be forgotten". Tamò e George lecionam que existem sinônimos e que há na doutrina quem diferencie cada um desses nomes:

In both the literature and political discussions, there is a lack of uniformity when it comes to defining the overall concept of "deletion" of personal data. While some use the terms "the right of oblivion", "the right to forget", "the right to be forgotten" or the "right to erasure" as synonyms, or at least sometimes interchangeably, others differentiate among the underlying concepts based on their legal rationale and scope. (TAMÒ; GEORGE, 2014).

Nessa seara, tecnicamente na língua portuguesa o caso emblemático de direito ao esquecimento da União Europeia trata-se de um direito de ser delistado ou desindexado dos motores de busca na internet. De forma breve, Bobadilla citando Rallo elucida que "además, no se pedía que se eliminase la información en el periódico, sino solamente que esta no fuese accesible por el mero hecho de escribir su nombre.(...) Por lo tanto, se pronunció a favor del 
ciudadano, exigiendo la desindexación de la información tanto de Google Inc. como de Google Spain” (RALLO apud BOBADILLA, 2019).

Vale mencionar, inclusive, que a questão evoluiu para uma discussão acerca da extraterritorialidade, isto é, se a informação deveria ser desindexada de Google Espanha ou de Google Inc. Otero esclarece o alcance da determinação, que de acordo com a legislação europeia e espanhola a responsabilidade é do Google Inc., pois, este "decide sobre los fines y medios del tratamiento, que en el caso del buscador de Google es la empresa Google Inc. Por su parte, Google Spain se limita a promocionar espacios publicitarios en el buscador, pero no tiene poder alguno de decisión sobre los datos, con lo que ha de ser excluida como responsable del tratamiento(...)" (OTERO, 2017).

Importa destacar o resumo do caso em tela apresentado, no acordão do TJUE:

Em 5 de março de 2010, M. Costeja González, de nacionalidade espanhola e domiciliado em Espanha, apresentou na AEPD uma reclamação contra a La Vanguardia Ediciones SL, que publica um jornal de grande tiragem, designadamente na Catalunha (Espanha) (a seguir «La Vanguardia»), e contra a Google Spain e a Google Inc. Esta reclamação baseava-se no facto de que, quando um internauta inseria o nome de M. Costeja González no motor de busca do grupo Google (a seguir «Google Search»), obtinha ligações a duas páginas do jornal da La Vanguardia de, respetivamente, 19 de janeiro e 9 de março de 1998, nas quais figurava um anúncio de uma venda de imóveis em hasta pública decorrente de um arresto com vista à recuperação de dívidas à Segurança Social, que mencionava o nome de M. Costeja González.15 Com esta reclamação, M. Costeja González pedia, por um lado, que se ordenasse à La Vanguardia que suprimisse ou alterasse as referidas páginas, para que os seus dados pessoais deixassem de aparecer, ou que utilizasse determinadas ferramentas disponibilizadas pelos motores de busca para proteger esses dados. Por outro lado, pedia que se ordenasse à Google Spain ou à Google Inc. que suprimissem ou ocultassem os seus dados pessoais, para que deixassem de aparecer nos resultados de pesquisa e de figurar nas ligações da La Vanguardia. Neste contexto, M. Costeja González alegava que o processo de arresto, de que fora objeto, tinha sido completamente resolvido há vários anos e que a referência ao mesmo carecia atualmente de pertinência.16 Por decisão de 30 de julho de 2010, a AEPD indeferiu a referida reclamação na parte em que dizia respeito à La Vanguardia, tendo considerado que a publicação por esta das informações em causa estava legalmente justificada, dado que tinha sido efetuada por ordem do Ministério do Trabalho e dos Assuntos Sociais e teve por finalidade publicitar ao máximo a venda em hasta pública, a fim de reunir o maior número possível de licitantes.17 $\mathrm{Em}$ contrapartida, deferiu esta mesma reclamação na parte em que dizia respeito à Google Spain e à Google Inc. A este respeito, a AEPD considerou que os operadores de motores de busca estão sujeitos à legislação em matéria de proteção de dados, uma vez que realizam um tratamento de dados pelo qual são responsáveis e atuam como intermediários da sociedade de informação. A AEPD considerou que estava habilitada a ordenar a retirada dos dados e a interdição de aceder a determinados dados, por parte dos operadores de motores de busca, quando considere que a sua localização e a sua difusão são suscetíveis de lesar o direito fundamental de proteção dos dados e a dignidade das pessoas em sentido amplo, o que abrange também a simples vontade da pessoa interessada de que esses dados não sejam conhecidos por terceiros. A AEPD considerou que esta obrigação pode incumbir diretamente aos 
operadores de motores de busca, sem que seja necessário suprimir os dados ou as informações do sítio web onde figuram, designadamente quando a manutenção dessas informações nesse sítio seja justificada por uma disposição legal.18 A Google Spain e a Google Inc. interpuseram dois recursos separados da referida decisão na Audiencia Nacional, que decidiu apensá-los.19 Este órgão jurisdicional expõe na decisão de reenvio que os referidos recursos suscitam a questão de saber quais as obrigações que incumbem aos operadores de motores de busca para efeitos da proteção dos dados pessoais das pessoas interessadas que não desejem que determinadas informações, publicadas em sítios web de terceiros e que contêm os seus dados pessoais que permitem ligar essas informações a essas pessoas, sejam localizadas, indexadas e postas à disposição dos internautas indefinidamente. A resposta a esta questão depende da forma como a Diretiva 95/46 deve ser interpretada, no contexto destas tecnologias que surgiram depois da sua publicação. (UNIÃO EUROPEIA, 2014)

Ocorre que o objetivo do autor não era um apagamento da história pessoal ou a negação da ocorrência do fato, mas, de outro modo, versava sobre a colocação da informação numa página e posição privilegiadas, facilmente acessáveis via provedor de pesquisa. Tal informação, segundo o acordão acima, já havia sido resolvida há tempos, portanto, não havia relevância em exteriorizar tal fato. Conforme decisão do TJUE, no caso Costeja, o Google realiza tratamento de dados e, desse modo, deve-se responsabilizar pela retirada da informação. Embora a GDPR ainda não estivesse em vigor, tomando por base a interpretação da Diretiva 95/46, o tribunal concluiu pelo tratamento de dados:

O artigo $4^{\circ}$, n. $^{\circ}$ 1, alínea a), da Diretiva $95 / 46$ deve ser interpretado no sentido de
que é efetuado um tratamento de dados pessoais no contexto das atividades de um
estabelecimento do responsável por esse tratamento no território de um
Estado-Membro, na aceção desta disposição, quando o operador de um motor de
busca cria num Estado-Membro uma sucursal ou uma filial destinada a assegurar a
promoção e a venda dos espaços publicitários propostos por esse motor de busca,
cuja atividade é dirigida aos habitantes desse Estado-Membro. (UNIÃO
EUROPEIA, 2014)

Espanha, Áustria, Itália e a Comissão Europeia ratificam o último entendimento: “O operador de um motor de busca é responsável pelo tratamento de dados efetuado por esse motor, uma vez que é ele que determina a finalidade e os meios desse tratamento. De outro lado, Google Espanha e Inc. se manifestaram informando que não realizam tratamento dos dados, pois não controlam os dados acessíveis na internet. Além disso, segundo os últimos buscadores, "esses motores tratam as informações acessíveis na Internet, no seu conjunto, sem fazer a seleção entre os dados pessoais e as outras informações" (UNIÃO EUROPEIA, 2014). Dessa forma, o entendimento de 2014 do TJUE é corroborado pelos artigos $17 \mathrm{n}^{\circ} 1$ e $\mathrm{n}^{\circ} 2$ e 21 $\mathrm{n}^{\mathrm{o}} 1$ da GDPR, os quais têm como regra o direito ao apagamento e o de oposição do titular dos dados. No destaque: 
Artigo 17. Direito ao apagamento dos dados («direito a ser esquecido»)1. O titular tem o direito de obter do responsável pelo tratamento o apagamento dos seus dados pessoais, sem demora injustificada, e este tem a obrigação de apagar os dados pessoais, sem demora injustificada, quando se aplique um dos seguintes motivos: a) Os dados pessoais deixaram de ser necessários para a finalidade que motivou a sua recolha ou tratamento; b) $\mathrm{O}$ titular retira o consentimento em que se baseia o tratamento dos dados nos termos do artigo 6. , n. 1, alínea a), ou do artigo 9. , n. 2, alínea a) e se não existir outro fundamento jurídico para o referido tratamento; c) $\mathrm{O}$ titular opõe-se ao tratamento nos termos do artigo 21. , n. 1, e não existem interesses legítimos prevalecentes que justifiquem o tratamento, ou o titular opõe-se ao tratamento nos termos do artigo 21. , n. 2; d) Os dados pessoais foram tratados ilicitamente; e) Os dados pessoais têm de ser apagados para o cumprimento de uma obrigação jurídica decorrente do direito da União ou de um Estado-Membro a que o responsável pelo tratamento esteja sujeito; f) Os dados pessoais foram recolhidos no contexto da oferta de serviços da sociedade da informação referida no artigo 8., n. 1. 2. Quando o responsável pelo tratamento tiver tornado públicos os dados pessoais e for obrigado a apagá-los nos termos do n. 1, toma as medidas que forem razoáveis, incluindo de caráter técnico, tendo em consideração a tecnologia disponível e os custos da sua aplicação, para informar os responsáveis pelo tratamento efetivo dos dados pessoais de que o titular dos dados lhes solicitou o apagamento das ligações para esses dados pessoais, bem como das cópias ou reproduções dos mesmos. (UNIÃO EUROPEIA, 2018)

Artigo 21. Direito de oposição: O titular dos dados tem o direito de se opor a qualquer momento, por motivos relacionados com a sua situação particular, ao tratamento dos dados pessoais que lhe digam respeito com base no artigo $6^{\circ}$, n. 1 , alínea e) ou f), ou no artigo $6^{\circ}$, n. 4 , incluindo a definição de perfis com base nessas disposições. O responsável pelo tratamento cessa o tratamento dos dados pessoais, a não ser que apresente razões imperiosas e legítimas para esse tratamento que prevaleçam sobre os interesses, direitos e liberdades do titular dos dados, ou para efeitos de declaração, exercício ou defesa de um direito num processo judicial. (UNIÃO EUROPEIA, 2018)

Assim, a regra do artigo 17 é a de que o titular tem o direito de obter o apagamento nas situações elencadas. Porém, excepcionalmente, tal regra não se aplica:

a) Ao exercício da liberdade de expressão e de informação; b) Ao cumprimento de uma obrigação legal que exija o tratamento prevista pelo direito da União ou de um Estado-Membro a que o responsável esteja sujeito, ao exercício de funções de interesse público ou ao exercício da autoridade pública de que esteja investido o responsável pelo tratamento; c) Por motivos de interesse público no domínio da saúde pública, nos termos do artigo 9. , n. 2, alíneas h) e i), bem como do artigo 9, n. 3 ; d) Para fins de arquivo de interesse público, para fins de investigação científica ou histórica ou para fins estatísticos, nos termos do artigo 89. , n. 1, na medida em que o direito referido no n. 1 seja suscetível de tornar impossível ou prejudicar gravemente a obtenção dos objetivos desse tratamento; ou e) Para efeitos de declaração, exercício ou defesa de um direito num processo judicial. (UNIÃO EUROPEIA, 2018)

Nessa esfera, a decisão europeia delimitou os exatos termos em que faria a análise. A decisão informa que irá examinar se Costeja tem o direito de ser delistado, ainda que o resultado das buscas não lhe cause prejuízo. A decisão esclarece que os direitos do autor 
prevalecem dado a atividade econômica desempenhada pelo provedor de pesquisa e, também, pela irrelevância da informação do indivíduo para o interesse público.

(...) importa designadamente examinar se a pessoa em causa tem o direito de que a
informação em questão sobre a sua pessoa deixe de ser associada ao seu nome
através de uma lista de resultados exibida na sequência de uma pesquisa efetuada a
partir do seu nome, sem que, todavia, a constatação desse direito pressuponha que a
inclusão dessa informação nessa lista causa prejuízo a essa pessoa. Na medida em
que esta pode, tendo em conta os seus direitos fundamentais nos termos dos artigos
$7 .^{\circ}$ e $8 .^{\circ}$ da Carta, requerer que a informação em questão deixe de estar à disposição
do grande público devido à sua inclusão nessa lista de resultados, esses direitos
prevalecem, em princípio, não só sobre o interesse económico do operador do
motor de busca mas também sobre o interesse desse público em aceder à
informação numa pesquisa sobre onome dessa pessoa. No entanto, não será esse
o caso se se afigurar que, por razões especiais como, por exemplo, o papel
desempenhado por essa pessoa na vida pública, a ingerência nos seus direitos
fundamentais é justificada pelo interesse preponderante do referido público em
ter acesso à informação em questão, em virtude dessa inclusão. (UNIÃO
EUROPEIA, 2014).

De outro lado, a decisão também elucida que caso o autor possua papel na vida pública é possível que os dados não sejam apagados, tendo em vista, que em alguns casos o interesse público deve preponderar sobre o individual. No mesmo sentido, a AEPD (Agencia Española de Protección de Datos Personales) já se manifestou reconhecendo que os indivíduos sem relevância pública não devem renunciar ao direito sobre a circulação de seus dados pessoais na web, conforme elucida Bobadilla "La AEPD se ha manifestado expresando que ningún ciudadano que sea personaje público, ni que sea objeto de hecho noticiable de relevancia pública, debe resignarse a que sus datos personales circulen por la red(...)" (GUASCH, 2015; SIMÓN, 2015; RALLO, 2014; HERNÁNDEZ, 2013 apud BOBADILLA, 2019).

Tecnicamente o termo right to be forgotten poderia ser considerado como inadequado para situações de desindexação de motor de busca, uma vez que, à primeira vista, pode-se confundir com right to delisting. O órgão francês CNIL (Commission Nationale de l'Informatique et des Libertés) já explicitou o que entende por right to delisting:

It prevents search engines to display some results following a search made on the basis of a person's name. It does not lead to deletion of the information on the source website. The original information remains unchanged and will still be found on search engines using other search terms, or by direct access to the publisher's original source". (FRANÇA, 2021).

Tal conceito parece mais próximo do de desindexação brasileiro, conforme será visto no tópico a seguir. 


\subsection{DIREITO AO ESQUECIMENTO E DESINDEXAÇÃO NO BRASIL}

Quanto à origem do direito ao esquecimento no Brasil, este teve seu reconhecimento na esfera penal antes da discussão acerca da sua possibilidade na esfera cível. A ideia refletida na seara penal nos remete ao caso Lebach, já citado. Um sujeito que cometeu um crime não deve admitir danos em função de pena imposta e já cumprida.

$\mathrm{Na}$ esfera cível, recentemente, o STF acabou por não reconhecer o direito ao esquecimento na tese de repercussão geral "Tema 786 - Aplicabilidade do direito ao esquecimento na esfera civil quando for invocado pela própria vítima ou pelos seus familiares. Relator: MIN. DIAS TOFFOLI no Leading Case: RE 1010606” (BRASIL, 2016). Nesta seara, em 2013, os civilistas já reconheceram sua existência e se manifestaram por meio do Enunciado $n^{\circ} 531$ da VI Jornada de Direito Civil:

Os danos provocados pelas novas tecnologias de informação vêm se acumulando
nos dias atuais. O direito ao esquecimento tem sua origem histórica no campo das
condenações criminais. Surge como parcela importante do direito do ex-detento à
ressocialização. Não atribui a ninguém o direito de apagar fatos ou reescrever a
própria história, mas apenas assegura a possibilidade de discutir o uso que é dado
aos fatos pretéritos, mais especificamente o modo e a finalidade com que são
lembrados. (BRASIL, 2013)

Importa destacar que, da mesma forma como ocorre na União Europeia, doutrina e jurisprudência brasileiras não possuem um alinhamento quanto ao conceito. A PGR no Recurso Extraordinário com Agravo no ${ }^{833.248 / R J}$ já se manifestou sobre a falta de clareza no que seja o direito ao esquecimento:

(...) com a devida vênia, não há precisão a respeito da normatividade, do âmbito de incidência e da definição do que seria o direito a esquecimento nem se encontra especificado de que maneira aquele "direito fundamental implícito" seria aplicável em matéria penal e nos demais domínios do Direito. O direito em exame manifestase em diversos campos do Direito, como o Direito Consumerista. O art. 43, § 1 o, da Lei de Defesa do Consumidor (Lei 8.078, de 11 de setembro de 1990), prevê modalidade de direito a esquecimento em prol dos consumidores, quanto a informações negativas em bases de dados.9 Na seara cível, há apenas dois precedentes do STJ nos quais se examinou especificamente essa figura: nestes autos, na análise pela 4a Turma do recurso especial dos recorrentes, e no recurso especial 1.334.097/RJ. (BARROS, 2016) 
No mesmo sentido, em 2015, Parentoni ${ }^{1}$ percorreu a etimologia do direito em comento e afirmou seu conceito, embora tenha esclarecido que as definições doutrinárias são múltiplas e distintas:

Direito ao esquecimento é a faculdade de obstar o processamento informatizado, a transferência ou publicação de dados pessoais, além de exigir que sejam apagados, sempre que a sua preservação esteja causando constrangimento ao sujeito envolvido, desde que não exista razão de interesse público que justifique a preservação (PARENTONI, 2015, p.546).

Para o último autor o esquecimento refere-se a dados informatizados. Contudo, é curioso destacar que o caso paradigmático do Brasil acerca do que se entende por direito ao esquecimento e sua aplicabilidade civil nem mesmo data da era das redes sociais e dos provedores de busca, nesse sentido, "o caso Aída Curi, que apesar de não estar relacionado à Internet, será um paradigma sobre a aplicação desse suposto direito dentro e fora das redes" (OLIVEIRA, 2020). Em fevereiro de 2021, o STF ao expor sua decisão na repercussão geral sobre o caso moldou, também, o que entende por direito ao esquecimento e aclarou que sua validade se aplica para meios digitais e analógicos:

É incompatível com a Constituição Federal a ideia de um direito ao esquecimento, assim entendido como o poder de obstar, em razão da passagem do tempo, a divulgação de fatos ou dados verídicos e licitamente obtidos e publicados em meios de comunicação social - analógicos ou digitais. Eventuais excessos ou abusos no exercício da liberdade de expressão e de informação devem ser analisados caso a caso, a partir dos parâmetros constitucionais, especialmente os relativos à proteção da honra, da imagem, da privacidade e da personalidade em geral, e as expressas e específicas previsões legais nos âmbitos penal e cível. (Grifo nosso) (BRASIL, 2021).

A seguir, apresentam-se os termos em que se deu a solicitação de esquecimento no caso emblemático brasileiro, Aída Curi. Tal resumo é apresentado, assim, como foi feito com o caso europeu para efeitos comparativos do contexto de utilização do direito em comento. $\mathrm{O}$ Ministro Edson Fachin em seu voto rememorou a pretensão da família:

Na ação original, os requerentes demandavam compensação pecuniária e reparação
material, em desfavor da requerida, em razão do uso não autorizado da imagem de
sua falecida irmã em programa televisivo denominado "Linha Direta Justiça". Os
recorrentes, alegando contrariedade aos arts. $1^{\circ}$, III; $5^{\circ}$, caput, III e X; e $220, \S 1^{\circ}$, da
Constituição da República, requerem que sejam julgados procedentes todos os
pedidos elencados na petição inicial, inclusive o de arbitramento de indenização por
dano moral e de condenação da recorrida a pagar indenização no valor fixado no
laudo pericial contábil, sem prejuízo da indenização pelo uso da imagem, nome e
história dos recorrentes, mesmo se a exploração destes atributos da personalidade
tiver ocorrido depois da sentença, até o trânsito em julgado. Requerem, ainda, que
seja declarada a ilegalidade do programa televisivo sob comento, por afrontar a

${ }^{1}$ C.f Parentoni, 2015, capítulo 3 a respeito da nomenclatura e etimologia. 
dignidade humana dos recorrentes, garantindo-lhes, expressamente, seu direito ao esquecimento no que tange ao assassinato de sua irmã. (CONJUR, 2021).

No plano nacional, além de o caso não ter ocorrido na era digital, Ruaro e Machado já questionaram a relevância pública de um programa de televisão revisitar tal história, ocorrida há tanto tempo: “(...) a caracterização do crime em questão como histórico já é, per si, questionável. O assassinato em questão não envolveu nenhum agente estatal, outrossim, sua relevância se deu mais pela brutalidade do ato do que por sua relevância pública, consistindo mais em evento revoltante que evento histórico" (RUARO; MACHADO, 2017, p. 218).

Diante do exposto, neste capítulo, o que se pretendeu demonstrar é que o contexto em que os fatos nacional e internacional ocorreram é bastante diverso. Sobretudo, porque o ora apresentado no plano nacional refere-se à exibição em televisão a qual, em 1998, não tinha o alcance que uma busca em provedor de pesquisa veio a adquirir na década seguinte. Dessa maneira a discussão acerca das diferenças entre os dois leading cases será aprofundada no tópico seguinte.

\subsection{PRINCIPAIS DIFERENÇAS DO CASO PARADIGMÁTICO DA UNIAO EUROPEIA E DO BRASIL}

Existem diferenças no casos Aída Curi e Costeja no que tange ao esquecimento. Vale destacar que na ação original os polos passivo e ativo e a pretensão são diferentes. No caso brasileiro a questão também versava sobre a possibilidade do reconhecimento do esquecimento para a família da vítima. De outro lado, no caso europeu, o esquecimento era para o autor. Utiliza-se o quadro a seguir para melhor compreensão:

\begin{tabular}{|c|c|c|}
\hline Polo ativo & Polo passivo & EMENTA \\
\hline Nelson Curi e outro(a/s) & $\begin{array}{l}\text { Globo Comunicação e e } \\
\text { Participações S/A } \\
\text { crime ocorrido há várias décadas. Ação indenizatória proposta por } \\
\text { familiares da vítima. alegados Danos morais. Direito ao esquecimento. } \\
\text { Debate acerca da harmonização dos princípios constitucionais da } \\
\text { liberdade de expressão e do direito à informação com aqueles que } \\
\text { protegem a dignidade da pessoa humana e a inviolabilidade da honra e } \\
\text { da intimidade. Presença de repercussão geral..( ARE 833248 RG, } \\
\text { Relator(a): Dias Toffoli, Tribunal Pleno, julgado em 11/12/2014) }\end{array}$ \\
\hline
\end{tabular}




\begin{tabular}{|c|c|c|}
\hline $\begin{array}{l}\text { Mario Costeja González e } \\
\text { AEPD }\end{array}$ & $\begin{array}{l}\text { Google Spain } \\
\text { Google Inc. }{ }^{2}\end{array}$ & $\begin{array}{l}\text { Dados pessoais - Proteção das pessoas singulares no que diz respeito } \\
\text { ao tratamento desses dados - Diretiva 95/46/CE - Artigos } 2 .^{\circ}, 4 .^{\circ} \\
12 .^{\circ} \text { e } 14 .^{\circ} \text { - Âmbito de aplicação material e territorial - Motores de } \\
\text { busca na Internet - Tratamento de dados contidos em sítios web } \\
\text { e Pesquisa, indexação e armazenamento desses dados } \\
\text { Responsabilidade do operador do motor de busca - Estabelecimento } \\
\text { no território de um Estado-Membro - Alcance das obrigações desse } \\
\text { operador e dos direitos da pessoa em causa - Carta dos Direitos } \\
\text { Fundamentais da União Europeia - Artigos } 7 .^{\circ} \text { e } 8 .^{\circ} \gg \text { (C 131/12 } \\
\text { Acórdão do tribunal de justiça (Grande Secção) } 13 \text { de maio de 2014) }\end{array}$ \\
\hline
\end{tabular}

Bobadilla explicita a configuração atual do direito ao esquecimento na União Europeia lastreando o reconhecimento desse direito na sociedade da informação. Segundo a autora a Europa manifesta-se pelo reconhecimento expresso do direito ao esquecimento na sociedade digital, além de entender que os buscadores fazem tratamento de dados e são responsáveis por isso. O esquecimento europeu é no sentido de desindexar informação em que a fonte original não aparece, de forma que o acesso a tal informação não será perdido, apenas não se terá acesso via provedor de pesquisa (BOBADILLA, 2019). No mesmo sentido, Frosio aclara de forma sintética o contexto europeu:

The Costeja decision is not about information being suppressed from the Internet. According to the WP29 Guidelines, the original information will always remain accessible, and no information is deleted from the original source. The right only affects the results obtained from searches made based on a person's name. That is, the original information will still be accessible using other search terms, or by direct access to the source. (FROSIO, 2017)

Acerca do tratamento de dados pelos motores de busca parte da doutrina tem sustentado a tese do caso Costeja. Consideram a relevância dos buscadores na sociedade informacional, conforme expõe Alcón, "los motores de búsqueda son robots, que desprenden sus tentáculos a toda la información existente en el universo web" (ALCÓN, 2016). Na mesma esfera, acerca da responsabilidade civil pelo tratamento, Otero professa que "es evidente que el buscador localiza, indexa, almacena, organiza y presenta los datos, por lo que está decidiendo sobre la finalidad y uso del tratamiento y debe ser considerado responsable" (OTERO, 2017).

Belay preleciona que, embora a tese majoritária seja o entendimento da Corte Europeia de que os buscadores realizam tratamento de dados, de outro lado, é possível ponderar que não há previsão expressa colocando os provedores de pesquisa como

\footnotetext{
${ }^{2}$ AEPD, no processo original, indeferiu a reclamação contra La Vanguardia.
} 
controlador no artigo 4 da GDPR, ainda que o artigo 17 trate dos controladores. Assim, ela infere que a posição dos buscadores "continuaria incerta" (BELAY, 2016). De outro lado, na doutrina europeia existem argumentos opostos, isto é, há quem sustente a não responsabilidade dos buscadores (GRAUER, 2015, pp. 1-12 apud ALCÓN, 2016).

No Brasil, o Superior Tribunal de Justiça (STJ) já firmou sua tese majoritária manifestando-se pela não responsabilização dos buscadores, embora reconheça a existência do esquecimento: "3. A jurisprudência desta Corte Superior tem entendimento reiterado no sentido de afastar a responsabilidade de buscadores da internet pelos resultados de busca apresentados, reconhecendo a impossibilidade de lhe atribuir a função de censor e impondo ao prejudicado o direcionamento de sua pretensão contra os provedores de conteúdo, responsáveis pela disponibilização do conteúdo indevido na internet” (BRASIL, STJ, REsp 1660168/RJ, 2018). Importa salientar que esta é a posição reiterada do STJ, embora, não seja absoluta. Inclusive no acordão em comento o mesmo Tribunal reconheceu a proteção dos dados pessoais, como exceção, em alinhamento com a doutrina da Corte Europeia:

Há, todavia, circunstâncias excepcionalíssimas em que é necessária a intervenção
pontual do Poder Judiciário para fazer cessar o vínculo criado, nos bancos de dados
dos provedores de busca, entre dados pessoais e resultados da busca, que não
guardam relevância para interesse público à informação, seja pelo conteúdo
eminentemente privado, seja pelo decurso do tempo. 5. Nessas situaçães
excepcionais, o direito à intimidade e ao esquecimento, bem como a proteção
aos dados pessoais deverá preponderar, a fim de permitir que as pessoas
envolvidas sigam suas vidas com razoável anonimato, não sendo o fato desabonador
corriqueiramente rememorado e perenizado por sistemas automatizados de busca. 6 .
O rompimento do referido vínculo sem a exclusão da notícia compatibiliza também
os interesses individual do titular dos dados pessoais e coletivo de acesso à
informação, na medida em que viabiliza a localização das notícias àqueles que
direcionem sua pesquisa fornecendo argumentos de pesquisa relacionados ao fato
noticiado, mas não àqueles que buscam exclusivamente pelos dados pessoais do
indivíduo protegido. 7. No caso concreto, passado mais de uma década desde o fato
noticiado, ao se informar como critério de busca exclusivo o nome da parte
recorrente, o primeiro resultado apresentado permanecia apontando link de notícia
de seu possível envolvimento em fato desabonador, não comprovado, a despeito da
existência de outras tantas informações posteriores a seu respeito disponíveis na rede
mundial. (...) (BRASIL, REsp 1660168/RJ, 2018) (Grifo nosso).

O Tribunal de Justiça de São Paulo (TJSP), em alinhamento com o STJ, mas em entendimento ainda mais restritivo, já considerou a ilegitimidade passiva dos provedores de pesquisa para tais demandas: “AÇÃO DE OBRIGAÇÃO DE FAZER. Ilegitimidade passiva da ré Google, pois não produziu o conteúdo ora impugnado e muito menos o hospedou, tratando-se de mera ferramenta de busca" (SÃO PAULO, 2019). Aponta-se que tais decisões foram pesquisadas antes da entrada em vigor da Lei Geral de Proteção de Dados (LGPD), 
assim, não se pode afirmar se houve alteração no entendimento da Corte Superior. Além disso, colaciona-se a ementa a seguir, a fim de explicitar que o STJ já utilizou o termo desindexação:

Ação: de obrigação de fazer, ajuizada por (...) em face das recorrentes, em que pleiteia a desindexação, nos resultados das aplicações de busca mantidas pelas recorrentes, de notícias relacionadas às suspeitas de fraude no XLI Concurso da Magistratura do Estado do Rio de Janeiro. Na inicial, a recorrida alega que a indexação desses conteúdos seria causa de danos a sua dignidade e a sua privacidade e, assim, requer a filtragem dos resultados de buscas que utilizem seu nome como parâmetro, a fim de desvinculá-la das mencionadas reportagens. (BRASIL, REsp 1660168/RJ, 2018).

Em sentido oposto, o não reconhecimento do direito ao esquecimento pelo STF abriu espaço para mais debates:

\begin{abstract}
Dessa forma, causou espécie o STF afirmar que o direito ao esquecimento agride a "memória do país", impõe o silêncio sobre a história ou fatos de interesse público, "fechando as cortinas do passado", pois o direito ao esquecimento não pretende abarcar fatos históricos e de interesse social, mas apenas notícias da esfera privada do indivíduo que perderam relevância social com o decurso do tempo e cuja republicação - ou permanente acessibilidade na internet - interfere gravemente na vida e no desenvolvimento da personalidade da pessoa afetada, por exemplo, gerando constrangimentos, embaraços aos familiares, dificultando a recolocação profissional, a ressocialização ou um simples recomeço. (FRITZ, 2021).
\end{abstract}

Embora, de outro lado, Oliveira sustente que existem outros preceitos capazes de fazer frente a esse tipo de demanda, ainda que a Corte Suprema tenha se manifestado em sentido contrário:

O Brasil já possui o referencial normativo apto a garantia dos direitos da personalidade que um suposto "direito ao esquecimento" visa tutelar. Por meio da aplicação dos artigos 20 e 21 do Código Civil, bem como diante da aplicação do que prevê o artigo $5^{\circ}$ da Constituição Federal, há garantia do direito à privacidade, à honra, à imagem e à dignidade, tal referencial normativo possibilita o pleito para a eventual remoção de conteúdo. (OLIVEIRA, 2020)

Diante do exposto, no Brasil, não há previsão expressa nem para o esquecimento, nem para a desindexação, desse modo, a jurisprudência engendra a base teórica desta argumentação acerca do caso brasileiro. Assim, embora o termo direito ao esquecimento tenha adquirido certa popularidade tanto no Brasil quanto na União Europeia, há quem entenda que este seja um termo genérico "despite its catchy terminology, the right to be forgotten can be understood as a generic term, bringing together existing legal provisions: the substantial right of oblivion and the rather procedural right to erasure derived from data protection" (TAMÒ; GEORGE, 2014). Oliveira sustenta no mesmo sentido: 
Apesar de se referir a desindexação de conteúdo do mecanismo de busca, a decisão ficou conhecida mundialmente e esse passou a ser um marco para o pleito de um "direito ao esquecimento" na Internet. Tanto isto é verdade que pouco tempo depois de proferida tal decisão o Google recebeu milhares de pedidos para a desindexação de conteúdo3. No Brasil, sob o pretexto de um "direito ao esquecimento" muitos pedidos são realizados e ações são ajuizadas. A ausência de parâmetros sólidos para estabelecer os limites desse suposto direito, contudo, proporciona incontáveis dúvidas e incertezas a respeito de sua tutela. (OLIVEIRA, 2020).

Em uma análise comparativa, por meio de casos relevantes da Bélgica, Holanda, Reino Unido, França, Alemanha, Polônia, Argentina, México, Chile, Brasil, Colômbia e Peru, Calster, Arreaza e Apers concluíram que existem diversos "direitos ao esquecimento": "RTBF appears to lack a clear conceptualisation, which then translates into multiple - and sometimes contradicting - approaches by domestic courts" (CALSTER; ARREAZA; APERS, 2018).

A partir de tal desajuste, os casos emblemáticos ora explicitados possuem alcances diferentes. O TJUE interpreta pela legitimidade passiva dos provedores de pesquisa no que tange à indexação de conteúdos, além de reconhecer que os últimos fazem tratamento de dados, de tal forma que devam ser responsabilizados pelos prejuízos decorrentes. Assim, denota-se que o caso paradigmático europeu abrange situação de desindexação de conteúdo. De outro lado, o caso emblemático brasileiro não se confunde com o último conceito e, portanto, não são situações análogas. O Caso Aída Curi trata de exibição em televisão, a qual não tem a perpetuidade e o alcance que uma busca em provedor de pesquisa possui na sociedade atual. No polo passivo da demanda europeia estão motores de busca e não jornais impressos ou veículos de televisão como no caso de repercussão geral brasileira.

Diante do exposto, será preciso aclarar muitos dos termos correlatos ao direito esquecimento a fim de se evitar a remanescente confusão. Parte da doutrina tem buscado elucidar esses conceitos. Lima, Ferreira e Souza, além de explicitar de que trata a desindexação, expõem que existem variados pleitos sob o mesmo instituto, qual seja o esquecimento:

Numa perspectiva oposta à finalidade da indexação, a desindexação trata da retirada ou exclusão de determinado conteúdo informativo de uma plataforma que contenham informações inverídicas ou violadoras do direito à privacidade e à intimidade (MORAES, 2016). Nas decisões relacionadas aos provedores de Internet e informações, criou-se o que se pode chamar de direito à desindexação. No mesmo sentido, Frajhof (2018, p. 24, grifo da autora) entende a desindexação como uma das estratégias disponíveis para a realização do direito ao esquecimento, [...] uma vez que as mais diversas soluções dadas pelos Tribunais, e pensadas pela doutrina, têm se utilizado deste direito para pleitear desde a desindexação, até a retirada de conteúdo de plataformas digitais, tudo sob o mesmo rótulo do 'direito ao esquecimento'. (LIMA; FERREIRA; SOUZA, 2020) 
No mesmo sentido, O Ministro Fachin, no julgamento da tese 786, elucidou que o instituto em comento possui múltiplas funções corroborando o que se pretendeu demonstrar neste trabalho:

O referente do termo "direito ao esquecimento" é essencialmente multifário. Tratase, em verdade, de um conceito guarda- chuva que recolhe uma pluralidade de direitos singulares que, não necessariamente, se adunam. Neste sentido, é possível afirmar que o direito ao esquecimento compreende, mas não se reduz nem aos tradicionais direitos à privacidade e à honra, nem tampouco ao direito à proteção de dados. Ele decorre, em verdade, de uma leitura sistemática do conjunto destas liberdades fundamentais. (CONJUR, 2021)

Em suma, a fim de responder ao objetivo deste trabalho afirma-se que existe distinção entre o caso brasileiro e o europeu, este tem permitido a desindexação dos buscadores pela via do Right to be forgotten, enquanto que, no Brasil, o caso paradigmático versa sobre situação distinta já apresentada. A tese 786 não exclui a possibilidade de solicitação de desindexação, como se poderia parecer a um olhar desatento. Nesse sentido, opina Fritz:

A decisão do STF, contudo, não abrange pedidos de desindexação, de modo que
hipóteses semelhantes à do BGH ou do Google Spain não são abrangidas pela Tese
786 . No voto, o relator isolou o direito à desindexação do direito ao esquecimento,
abrindo espaço para a análise desses casos pelo juiz. Porém, sob o aspecto teórico,
parece-me questionável que ambos os direitos sejam incomunicáveis, pois,
conquanto distintos, eles decorrem, em última análise, do direito à autodeterminação
informacional do indivíduo, como frisado pelos ministros Edson Fachin e Gilmar
Mendes, em sintonia com a melhor doutrina europeia. Dessa forma, melhor teria
sido, a meu ver, se o STF, seguido a linha do tribunal alemão, tivesse reconhecido a
existência do direito ao esquecimento, mas negado no caso concreto.(FRITZ, 2021).

Em suma, demonstrou-se que existem formas variadas de se entender o conceito de direito ao esquecimento o qual, consequentemente, é impreciso para os casos de desindexação, embora a nomenclatura tenha ganhado imensa popularidade tanto no Brasil quanto na União Europeia. Verificou-se que não existem definições e usos uniformes, o que tem aproveitado o gozo do termo em diversas situações que de alguma maneira podem estar aproximadas, apesar de não serem idênticas.

\section{CONSIDERAÇÕES FINAIS}

Diante do exposto, extrai-se que o instituto em questão está há algum tempo em debate, ainda que, sob diferentes formas, contextos e nomenclaturas. Nesse sentido, diante das diversas terminologias e usos ora apresentados para o direito ao esquecimento, tem-se que existe diferença na aplicação dos conceitos brasileiro e europeu, de tal modo que fica 
cumprido o objetivo proposto. Além disso, o caso internacional refere-se ao que a doutrina tem entendido por desindexação, enquanto que o caso paradigmático brasileiro não é capaz de abarcar a relevância dos buscadores na web, sobretudo pela capacidade dos últimos de perpetuar informação.

Nesse sentido, diante das questões sociais da era informacional, verifica-se que há certa imprecisão quanto à nomenclatura tanto na doutrina quanto na jurisprudência nacional e internacional. Embora nos últimos anos se tenham empreendido esforços para melhor designar esse conceito.

A permanência das informações pretéritas na internet tem incomodado alguns enquanto outros temem que sua desindexação seja meio de censura ou de dominação dando poder a grandes empresas de tecnologia.

Em suma, institutos de épocas e realidades distintas foram julgados sob o mesmo conceito. Doutrina e jurisprudência ainda não conseguiram definir qual o alcance do instituto. A análise comparativa conclui que não há uniformidade quanto às terminologias ora apresentadas. A falta de alinhamento teórico implica em imprecisão quanto ao alcance da tutela jurídica do instituto. Nesse sentido, o esquecimento tem servido a diversas demandas, o que gera incertezas quanto a quais pleitos são ou não tuteladas sob tal égide. Assim, embora o STF tenha julgado a tese $n^{\circ} 786$ pelo não reconhecimento do direito em comento, há possibilidade de que a Corte Constitucional tenha entendimento de que desindexação e esquecimento sejam figuras distintas, uma vez que o caso nacional não envolveu tal discussão.

\section{REFERÊNCIAS}

ALCON, A. P. El derecho al olvido en internet. El fenómeno de los motores de búsqueda. Opin. jurid., Medellín , v. 15, n. 29, p. 243-260, June 2016 . Disponível em: http://www.scielo.org.co/scielo.php?script=sci_arttext\&pid=S1692-

25302016000100013\&lng=en\&nrm=iso. Acesso em: 4 de abril de 2021

BARRoS, R. J. M. de. Parecer No 156.104/2016 PGR. 2016. Disponível em: https://www:conjur:com:br/dl/parecer-pgr-direito-esquecimento:pdf. Acesso em: 4 de abril de 2021

BELAY, R. C. M. O direito ao esquecimento e o regulamento geral sobre a proteção de dados: entre garantias e ameaça à liberdade de expressão. Revista do programa de Direito da União Europeia. Vol.6. 2016. 49 - 66 p. Disponível em: 
https://bibliotecadigital.fgv.br/ojs/index.php/rpdue/article/view/68238/65864. Acesso em: 4 de abril de 2021

BOBADILLA, A. M. El derecho al olvido digital: una brecha entre Europa y Estados Unidos. Revista de Comunicacion. v. 18, n. 1, p. 259 - 276, 2019. Disponível em: https://doi:org/10:26441/RC18:1-2019-A13. Acesso em: 4 de abril de 2021

Los derechos digitales en Europa tras la entrada en vigor del Reglamento de Protección de Datos Personales: Un antes y un después para el derecho al olvido digital. Estudios constitucionales, Santiago , v. 18, n. 2, p. 121-150, 2020 . Disponivel em https://scielo.conicyt.cl/scielo.php?script=sci_arttext\&pid=S0718-

52002020000200121\&lng=es\&nrm=iso. Acesso em: 4 de abril de 2021

BRASIL. VI Jornada de Direito Civil. Enunciado 531. 2013. Disponível em: https://www:cjf:jus:br/enunciados/enunciado/142. Acesso em: 4 de abril de 2021

Superior Tribunal de Justiça. REsp 1660168/RJ, Rel. Min. Nancy Andrighi, Terceira turma, j. em 08/05/2018. 2018. Disponível em: https://ww2.stj.jus.br/processo/revista/documento/mediado/?componente=ITA\&sequencial=1 $628798 \&$ num_registro $=201402917771 \&$ data $=20180605 \&$ formato=PDF. Acesso em 27/05/2020.

Supremo Tribunal Federal. Tema 786 - Aplicabilidade do direito ao esquecimento na esfera civil quando for invocado pela própria vítima ou pelos seus familiares. 2016. Disponível em: http:// www:stf:jus:br/portal/jurisprudenciaRepercussao/verAndamentoProcesso:asp?incidente= 5091603\&numeroProcesso $=1010606 \&$ classeProcesso $=$ RE\&numeroTema $=786$. Acesso em: 5 de abril de 2021

\section{Supremo Tribunal Federal. STF conclui que direito ao esquecimento é incompatível com a Constituição Federal. 2021. Disponível em: https://portal:stf:jus:br/noticias/ verNoticiaDetalhe:asp?idConteudo=460414\&ori=1. Acesso em: 6 de abril de 2021}

CALSTER, G. V.; ARREAZA, A. G.; APERS, E. Not just one, but many 'rights to be forgotten'. Internet Policy Review .v. 7, n. 2, 2018. Disponível em: https://policyreview.info/articles/analysis/not-just-one-many-rights-be-forgotten.Acesso em: 4 de abril de 2021

CONJUR. Voto do Ministro Edson Fachin no RE 1010606 / RJ Disponível em: https://www.conjur.com.br/dl/voto-fachin1.pdf. Acesso em 09 de abril de 2021.

FRANÇA. Commission Nationale de l'Informatique et des Libertés. Questions on the right to delisting. 2021. Disponível em: https://www:cnil:fr/fr/node/15815. Acesso em: 3 de abril de 2021

FRITZ, K. N. Direito ao esquecimento está implícito na CF, diz especialista. Migalhas. 2021. Disponível em: https://www:migalhas:com:br/quentes/340757/direitoao-esquecimentoesta-implicito-na-cf-diz-especialista. Acesso em: 5 de abril de 2021 
FROSIO, G. F. The right to be forgotten: much ado about nothing.. Colorado Technology Law Journal 307 (2017) Disponível em: https://perma:cc/C9W2-. Acesso em: 30 de março de 2021

LIMA, P. R. S.; FERREIRA, J. R. S.; SOUZA, E. D. de. Direito ao esquecimento e desindexação da informação. Logeion: Filosofia da Informação. v. 7, n. 1, p. 28 - 48, 9 2020. Disponível em: https: //doi:org/10:21728/logeion:2020v7n1:p28-48. Acesso em: 03 de abril de 2021

OLIVEIRA, C. C. O Brasil precisa de um "direito ao esquecimento"? Instituto de tecnologia e Sociedade do Rio. ITS FEED. 2020. Disponível em: https://feed:itsrio:org/o-brasil-precisade-um-direito-aoesquecimento-8b702906e4a6. Acesso em: 4 de abril de 2021

Eliminação, desindexação e esquecimento na internet [livro eletrônico]. $1^{\circ}$. ed. São Paulo: Thomson Reuters Brasil,, 2020.

OTERO, J. M. La aplicación del derecho al olvido en españa tras la stjue google contra AEPD y Mario Costeja. Iuris Tantum Revista Boliviana de Derecho 2017. 112 - 133 p. Disponível em: http://www:scielo:org:bo/ scielo:php?script=sci_arttext\&pid=S207081572017000100004\&lang=en. Acesso em:3 de abril de 2021.

PARENTONI, L. N. O Direito ao Esquecimento (Right to oblivion). In. DE LUCCA, Newton; SIMÃO FILHO, Adalberto; Cíntia Rosa Pereira de (coords.) Direito \& Internet III - Tomo I: Marco Civil da Internet (Lei n. 12.965/2014) - São Paulo. Quartier Latin, 2015, p. 539. Disponível em: https://www.researchgate.net/profile/LeonardoParentoni/publication/299821661_O_Direito_ao_Esquecimento_Right_to_Oblivion/links/571 7ab9308ae986b8b79e0b8/O-Direito-ao-Esquecimento-Right-to-Oblivion.pdf. Acesso em 12 de abril de 2021.

PÉREZ, T.A. Memoria versus olvido: la paradoja de internet. Universum. Vol. $31 \mathrm{n}^{\mathbf{o}} 1$ 2016,p.31-44.Disponível

em:. https://scielo.conicyt.cl/scielo.php?script=sci_arttext\&pid=S0718-

23762016000100003\&lng=en\&nrm=iso. Acesso em: 4 de abril de 2021

RINCÓN, A. C. G. An approach to the legal configuration of the right to be forgotten on the internet. An analysis from the judgment of the cjeu vs google. Boletin Mexicano de Derecho Comparado.v. 51, n. 156, p. 1449 - 1475, 2019. Disponível em: https://eurlex:europa:eu/legalcontent/EN/TXT/PDF/?uri=CELEX:. Acesso em: 6 de abril de 2021

RUARO, R. L; MACHADO, F. I. de S. Ensaio a propósito do direito ao esquecimento: limites, origem e pertinência no ordenamento jurídico brasileiro. Revista do Direito Público, Londrina, v. 12, n. 1, p.204-233, abr. 2017. Disponível em: http://www.mpsp.mp.br/portal/page/portal/documentacao_e_divulgacao/doc_biblioteca/bibli_ servicos_produtos/bibli_informativo/bibli_inf_2006/Rev-Dir-Pub_v.12_n.1.07.pdf. Acesso em 12 de abril de 2021

SÃO PAULO. Tribunal de Justiça. Apelação Cível 1076916-25.2018.8.26.0100; Rel: Maria de Lourdes Lopez Gil Órgão Julgador: 7ª Câmara de Direito Privado j.25/09/2019. 
https://esaj.tjsp.jus.br/cjsg/getArquivo.do?cdAcordao=12933165\&cdForo=0. Acesso em 28 de maio de 2020

TAMÒ, A.; GEORGE, D. Oblivion, Erasure and Forgetting in the Digital Age. Journal of Intellectual Property, Information Technology and E-Commerce Law v. 5, n. 2, 92014. Disponível em: http://www:jipitec:eu/issues/jipitec-5-2-2014/3997. Acesso em: 3 de abril de 2021

UNIÃO EUROPEIA. Tribunal de Justiça. Processo C-131/12. Google Spain SL e Google Inc. c. Agencia Española de Protección de Datos e Mario Costeja González .2014. Disponível em:http://curia.europa.eu/juris/document/document.jsf?text=\&docid=152065\&pageIndex $=0 \&$ doclang $=P T \&$ mode $=1$ st $\&$ dir $=\& o c c=$ first $\&$ part $=1 \&$ cid $=7265264$. Acesso em: 20 de junho de 2020

Artigo 17 Direito ao apagamento dos dados (direito a ser esquecido). General Data Protection Regulation (GDPR). 2018. Disponível em: https://gdpr:algolia:com/pt/gdprarticle-17. Acesso em: 4 de abril de 2021

Artigo 17 GDPR - Right to erasure ('right to be forgotten'). General Data Protection Regulation (GDPR). 2018. Disponível em: https://gdpr-info:eu/art-17-gdpr/. Acesso em: 6 de abril de 2021

Artigo 21.Direito de oposição. General Data Protection Regulation (GDPR). 2018. Disponível em: https://gdpr.algolia.com/pt/gdpr-article-21. Acesso em: 13 de abril de 2021. 